\title{
CONCRETO TRANSLÚCIDO COM ADIÇÃO DE FIBRAS ÓPTICAS
}

\author{
TRANSLUCENT CONCRETE WITH ADDITION OF OPTICAL FIBERS
}

Camila Aparecida Fernandes de Freitas ${ }^{1}$

Gabriela Cassol ${ }^{2}$

\section{RESUMO}

Com a busca por novos materiais para a preservação dos recursos naturais para a construção civil, um novo material vem chamando atenção por sua proposta. Criado em 2001 na Húngria, o concreto translúcido é um material que traz uma inovação, com a adição das fibras ópticas ele permite que a luz o penetre. Vale lembrar, que apesar de ser chamado originalmente de concreto translúcido, o material é constituído por uma mistura de argamassa com a adição das fibras ópticas poliméricas. O principal questionamento levantado neste trabalho é qual das duas fibras ópticas, a fibra óptica de vidro ou a polimérica adicionadas ao bloco de argamassa tem mais translucidez? O presente trabalho teve como premissa desenvolver uma pesquisa comparativa entre fibra óptica de vidro e a fibra óptica polimérica para verificar qual apresentaria maior luminosidade através da argamassa. Como é um material inovador necessita de várias pesquisas e em cima dos trabalhos que já foram desenvolvidos, nenhum realizou a comparação. Dessa maneira, foi elaborado um estudo da dosagem da argamassa, com base nos estudos já realizados. Na primeira fase, realizou-se uma pesquisa bibliográfica e foi definida a metodologia que foi executada nesta segunda fase do trabalho. Nesta segunda etapa foram realizados os ensaios de caracterização dos materiais, a dosagem da argamassa, ensaios no estado fresco da argamassa e a confecção dos protótipos com adições das fibras que foram submetidos a ensaios laboratoriais para análise dos resultados de resistência à compressão, e o ensaio de luminosidade.

Palavras-Chave: Concreto translúcido. Fibras ópticas. Translucidez.

\footnotetext{
${ }^{1}$ Acadêmica do Curso de Engenharia Civil da Universidade Alto Vale do Rio do Peixe (UNIARP). Email: camilabuenos2@hotmail.com.

2 Professora Orientadora. Graduado em Engenharia Civil, pela Universidade do Oeste de Santa Catarina (UNOESC), Mestrado em Engenharia Civil, pela Universidade Estadual Paulista "Júlio de Mesquita Filho" (UNESP) campus de Ilha Solteira e docente do Curso de Engenharia Civil da Universidade Alto Vale do Rio do Peixe.
} 


\section{ABSTRACT}

With the search for new materials for the preservation of natural resources for civil construction, a new material has been drawing attention to its proposal. Created in 2001 in Hungary, translucent concrete is a material that brings innovation, with the addition of optical fibers it allows light to penetrate. It is worth remembering that, although originally called translucent concrete, the material consists of a mortar mix with the addition of the polymer optical fibers. The main question raised in this work is which of the two optical fibers, the glass fiber optic or the polymer fiber added to the mortar block has more translucency? The present work had as premise to develop a comparative research between optical fiber of glass and the polymeric optical fiber to verify which would present greater luminosity through the mortar. Because it is an innovative material, it requires several researches and, on top of the works that have already been developed, none have made the comparison. In this way, a study of the mortar dosage was elaborated, based on the studies already carried out. In the first phase, a bibliographical research was carried out and the methodology that was executed in this second phase of the work was defined. In this second stage, the characterization of the materials, the dosing of the mortar, the fresh state of the mortar and the preparation of the prototypes were performed with additions of the fibers that were submitted to laboratory tests to analyze the results of resistance to compression, and the test of brightness.

Keywords: Translucent Concrete. Optical fibers. Translucency.

\section{INTRODUÇÃO}

Constantemente no Brasil e em todo o mundo, há uma busca por novos materiais para a construção civil, com isso surgem às pesquisas e as inovações, visando uma maior economia e a preservação dos recursos naturais.

Essa busca é feita para vários materiais da construção civil, mas mais especificamente para o concreto, que é um elemento da construção desde o século $X X$, esse material hoje é o segundo mais consumido pelo homem, perde apenas para a água, ele é dia após dia estudado para que venham se desenvolver novas incorporações para assim criar novos materiais que sejam benéficos para a sociedade (RESTREPO, 2013).

Logo, em 2001, surge o concreto translúcido, desenvolvido na Húngria, através de um bloco de concreto translúcido, feito pelo arquiteto húngaro Aron Losonczi, segundo o autor o concreto translúcido, possui resistência mecânica que 
se assemelha ao concreto convencional, e devido à adição das fibras, permite ver as silhuetas do lado contrário (TUTIKIAN, 2009).

Uma questão essencial a ser descrita é quanto à nomenclatura do material. Apesar de ser chamado de concreto translúcido, o LitraCon é, originalmente, constituído por uma mistura de argamassa com adição de fibra óptica não sendo utilizado, portanto, agregado graúdo. Acredita-se então, que a razão para esse material ser chamado de concreto translúcido pela empresa que originalmente o desenvolveu seja para efeitos de marketing, a fim de causar maior impacto na sua divulgação (HENRIQUES, 2013).

Nos blocos confeccionados com concreto translucido, as fibras ópticas ficam encarregadas de transportar a luz de um lado para o outro, sendo assim, haveria uma certa economia de energia, devido ao aproveitamento da luz do sol (RESTREPO, 2013).

Essas fibras estão disponíveis nos mais variados tipos para fins comerciais e uso experimental, sendo: as fibras metálicas, de vidro, sintéticas, e as naturais (HENRIQUES, 2013).

Logo, surge o seguinte problema: Qual das duas fibras, de vidro ou a polimérica, apresentará maior translucidez no concreto?

O presente trabalho tem como premissa desenvolver uma pesquisa comparativa entre fibra óptica de vidro e a fibra óptica polimérica para verificar qual apresenta maior luminosidade através do bloco de argamassa, como é um material inovador necessita de várias pesquisas e em cima dos trabalhos que já foram desenvolvidos, nenhum realizou a comparação.

Como o concreto é considerado um dos mais importantes materiais utilizados na construção civil, a pesquisa busca conhecimento nessa nova tecnologia. O concreto translúcido pode ser utilizado tanto para fins estéticos como para fins estruturais, e a maior vantagem dele é a utilização da luz natural que penetra o concreto através das fibras. Como no Brasil esse material é considerado novo o presente estudo tentará especificar qual das duas fibras juntamente com o bloco de argamassa terá translucidez através do protótipo. 


\section{MATERIAIS E MÉTODOS}

Este capítulo irá apresentar o programa experimental realizado no Laboratório de Materiais e Solos da Universidade Alto Vale do Rio do Peixe (UNIARP) em Caçador. Inicialmente foi realizado a caracterização do agregado miúdo, após foi confeccinado o traço da argamassa. Em seguida foram realizados os ensaios no estado fresco da argamassa e logo após os corpos de prova foram moldados, em seguida foi realizado o ensaio no estado endurecido da argamassa dos corpos de prova aos 07,14 e 28 dias para analisar a resistência à compressão e a tração na flexão. Por fim foram moldados os protótipos com argamassa e as fibras ópticas poliméricas e fibras ópticas de vidro para o ensaio de luminosidade.

MATERIAIS

\section{Cimento Portland}

Neste trabalho foi utilizado o cimento Portland CP \| Z - 32, que foi encontrado com facilidade, sendo empregado em obras diversificadas.

De acordo com a NBR 11578 (ABNT, 1997) o cimento CP II Z - 32 contém, de 94 a 76\% de clínquer mais sulfatos de cálcio, 6 a 14\% material pozolânico e de 0 a $10 \%$ material carbonático.

\section{Agregado miúdo}

O agregado miúdo que foi utilizado na realização deste estudo, foi a areia fina, procedente da região de Porto União - Santa Catarina, com massa específica de $2,66 \mathrm{~g} / \mathrm{cm}^{3}$, massa unitária de $1,468 \mathrm{~g} / \mathrm{dm}^{3}$ e módulo de finura de 1,52. 


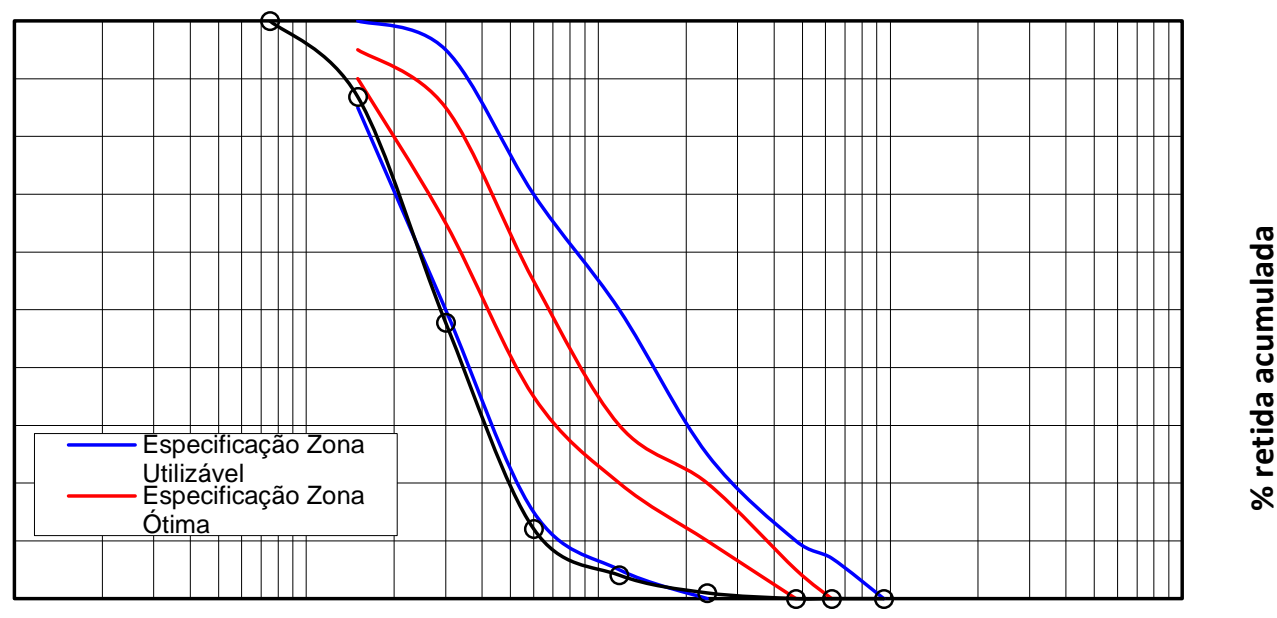

abertura $(\mathrm{mm})$

Figura 1 - Curva granulométrica do agregado miúdo

Fonte: O próprio autor

\section{Fibras Ópticas}

Para a comparação do concreto translucido foram utilizadas dois tipos de fibra óptica neste trabalho, sendo a fibra óptica de vidro e a fibra óptica de plástico.

A fibra óptica de vidro utilizada em um dos protótipos foi da empresa ZTT Fibra Óptica localizada em Videira/SC, a fibra utilizada será a SM G.652D (Zero pico d'água - LWP) - mais usual no mercado de Telecom, com ampla utilização nas redes externas. Por meio de processos industriais de produção que diminuem ou eliminam o efeito "pico d'água", permite que a faixa de comprimento de onda de 1400nm seja utilizada para tráfego de sistemas ópticos com baixa atenuação, o que possibilita a utilização em toda a faixa de comprimento de onda, desde $1310 \mathrm{~nm}$ até $1625 \mathrm{~nm}$, faixas nas quais os equipamentos CWDM atuam (ZTT, 2018).

A fibra óptica de plástica utilizada foi obtida através de uma empresa brasileira distribuidora de abajures fabricados na China, não sendo possível obter informações do fabricante e composição do material.

\section{Água de Amassamento}

A água de amassamento utilizada no desenvolvimento dos traços do concreto em estudo éde procedência do poço artesiano que abastece a UNIARP em 
Caçador - Santa Catarina.

MÉTODOS

\section{Método de Dosagem dos Traços de Concretos}

O estudo de dosagem do traço de argamassa foram realizados no Laboratório de Materiais e Solos da Universidade Alto Vale do Rio do Peixe - UNIARP.

Foi adotado um único traço, dentre as pesquisas consultadas, optou por usar o traço 1:2,22:0,5 (HENRIQUES, 2013).

\section{Ensaios da Argamassa}

O ensaio para determinar a consistência da argamassa no estado fresco que foi realizado está descrito na NBR NM 13276 (ABNT, 2002): Argamassa para assentamento e revestimento de paredes e tetos - Preparo da mistura e determinação do índice de consistência.

Para a retenção de água da argamassa no estado fresco foi determinada de acordo com a NBR NM 13277 (ABNT, 1995): Argamassa para assentamento de paredes e revestimento de paredes e tetos - Determinação da retenção de água.

Para a densidade da massa da argamassa no estado fresco foi determinada de acordo com a NBR NM 13278 (ABNT, 1995): Argamassa para assentamento de paredes e revestimento de paredes e tetos - Determinação da densidade de massa e do teor de ar incorporado.

Na confecção dos protótipos tanto para a fibra óptica de vidro como para a fibra óptica de plástico, foram fabricados pequenas placas de isopor no tamanho $12 \times 7 \times 6$ onde as fibras serão distribuídas sobre as camadas de argamassa e depois foi cortado o bloco ao meio.

O ensaio de resistência à compressão da argamassa foi determinada pelo rompimento dos corpos de prova, segundo método expresso na NBR 13279 (ABNT, 2005): Argamassa para assentamento e revestimento de paredes e tetos Determinação da resistência à tração na flexão e à compressão.

A resistência à tração na flexão da argamassa foi determinada pelo 
rompimento dos corpos de prova, segundo método expresso na NBR 13279 (ABNT, 2005): Argamassa para assentamento e revestimento de paredes e tetos Determinação da resistência à tração na flexão e à compressão.

Por fim foi realizado o ensaio de luminosidade que pretende demonstrar a transmissão de luz através da argamassa com fibra óptica, na busca de uma avaliação quantitativa. As aferições luminotécnicas foram realizadas de acordo com a NBR 5461 (ABNT, 1991), por meio de aparelho adequado (luxímetro).

\section{RESULTADOS E DISCUSSÕES}

TRABALHABILIDADE

Para determinação da trabalhabilidade da argamassa, foi seguido o procedimento descrito NBR NM 13276 - Trabalhabilidade, logo em seguida foi elaborado o Gráfico 01.

Gráfico 1: Consistência do traço de argamassa

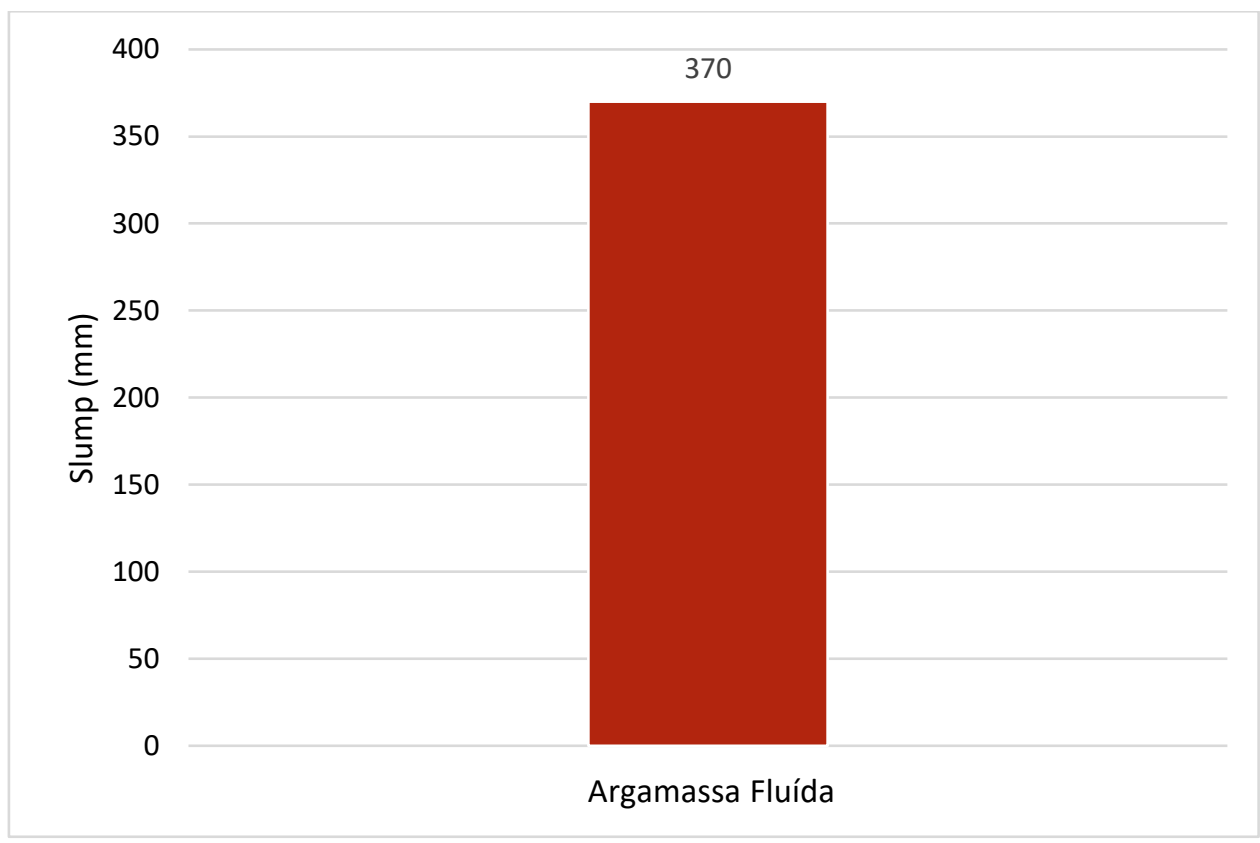

Fonte: O próprio autor

Vários autores classificam as argamassas, segundo a consistência em três 
tipos: secas é a pasta que preenche os vazios entre os grãos, as plásticas que a pasta forma uma fina película e atua como lubrificante na superfície dos agregados, e as fluídas onde os grãos ficam imersos na pasta.

A consistência é diretamente determinada pelo conteúdo de água, sendo influenciada pelos seguintes fatores: relação água/aglomerante, relação aglomerante/areia, granulometria da areia, natureza e qualidade do aglomerante (SILVA, 2008).

De acordo com Silva (2008), argamassas que possuem um índice de consistência superior a $360 \mathrm{~mm}$ podem ser consideradas como fluídas. Conforme esperado ela obteve um amplo espalhamento da argamassa na mesa de consistência durante o ensaio.

Figura 1: Slump Argamassa

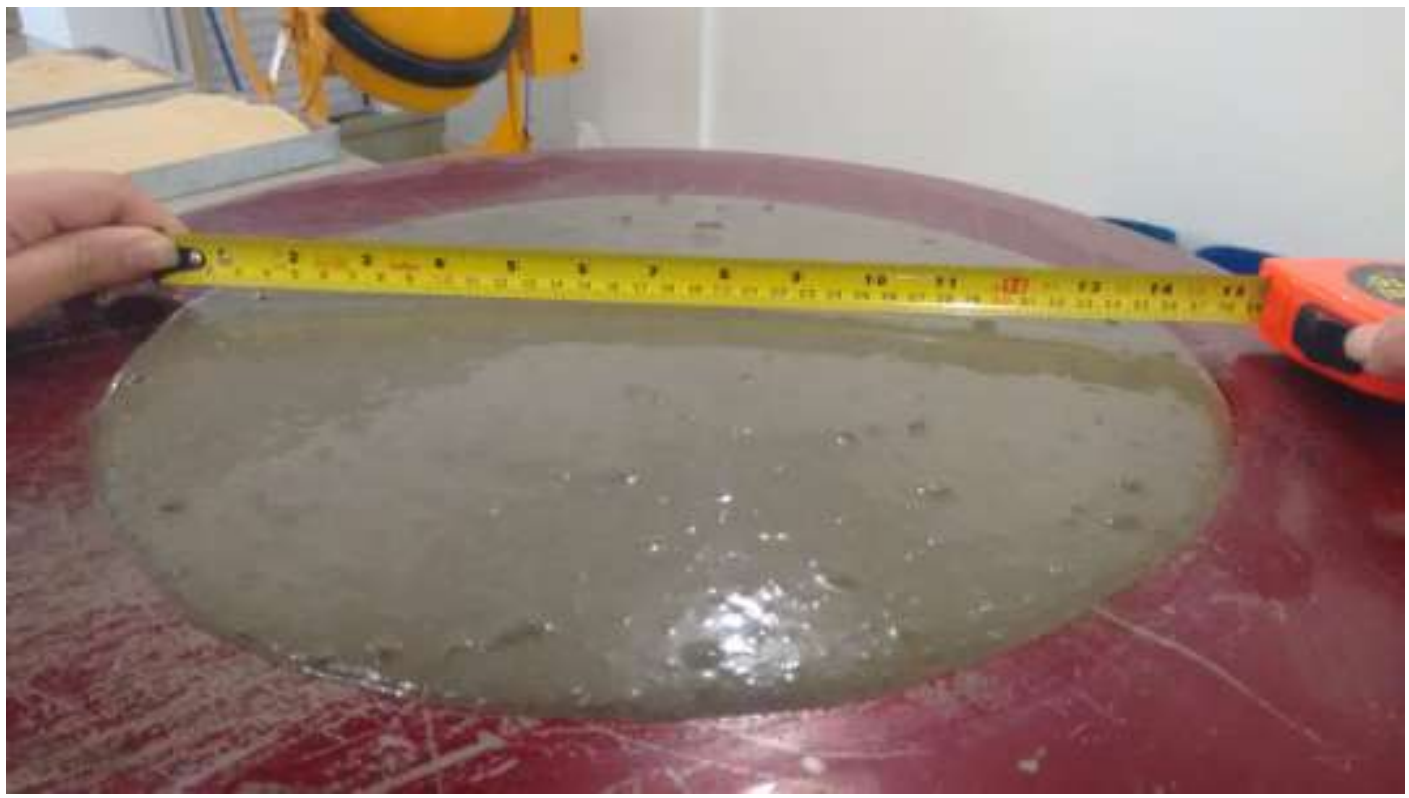

Fonte: O próprio autor

\section{RETENÇÃO DE ÁGUA}

Para a determinação da retenção de água da argamassa no estado fresco foi seguido os procedimentos descritos na NBR NM 13277 (ABNT, 1995) - Retenção de água. Em seguida, foi elaborada a tabela abaixo.

Tabela 1: Retenção de água da argamassa

Amostra 01 
Massa total de água acrescentada à mistura (g)

1171,89

\begin{tabular}{ll}
\hline Massa de argamassa (g) & 5990,00 \\
\hline Fator água/argamassa fresca & 0,163628595 \\
\hline
\end{tabular}

Massa do conjunto de discos molhados de papel-filtro (g)

17,42

Massa do conjunto de discos secos (g)

7,88

Massa do molde com argamassa (g)

960,09

\begin{tabular}{lc}
\hline Massa do molde vazio (g) & 96,01 \\
\hline Retenção de água (\%) & 93,25
\end{tabular}

Fonte: O próprio autor

\section{DENSIDADE DA MASSA}

Para a determinação da densidade da massa da argamassa no estado fresco foi seguido os procedimentos descritos na NBR NM 13278 (ABNT, 1995) - Densidade da massa. Em seguida, foi elaborada a tabela abaixo.

Tabela 2: Densidade da massa

Amostra 01

Massa do recipiente, contendo a argamassa de ensaio (g) 1717,06

Massa do recipiente vazio (g)

887,64

Volume do recipiente $\left(\mathrm{cm}^{3}\right)$

405,18

Densidade da argamassa

2,05

Fonte: O próprio autor

\section{CONFECÇÃO DOS PROTÓTIPOS}

Os protótipos tanto para a fibra óptica de vidro como para a fibra óptica de plástico, foram fabricados quatro pequenas placas de isopor no tamanho de 12×7×6 
$\mathrm{cm}$, em seguida foram cortadas às fibras ópticas em um tamanho um pouco menor da forma como ilustra a figura 10 para logo depois fazer a mescla de argamassa, onde em cada protótipo foi colocado três camadas de fibras ópticas em sequência com a argamassa.

Foram colocadas 4,59 gramas de fibra óptica de vidro e fibra óptica de plástico cada uma em seu protótipo. Depois do tempo de cura da argamassa com os blocos já desformados, eles foram cortados ao meio.

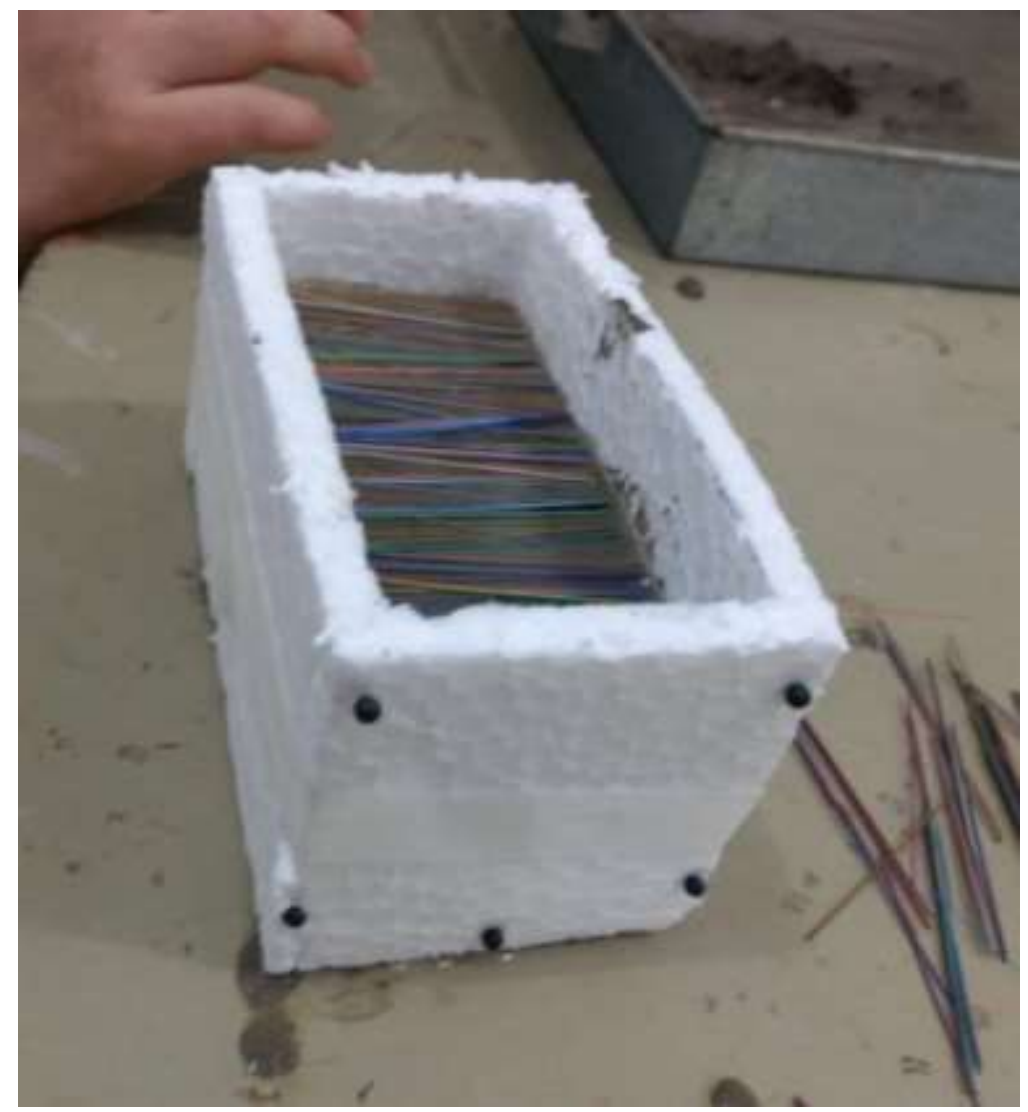

Figura 2: Molde de isopor com as fibras ópticas de vidro

Fonte: O próprio autor 


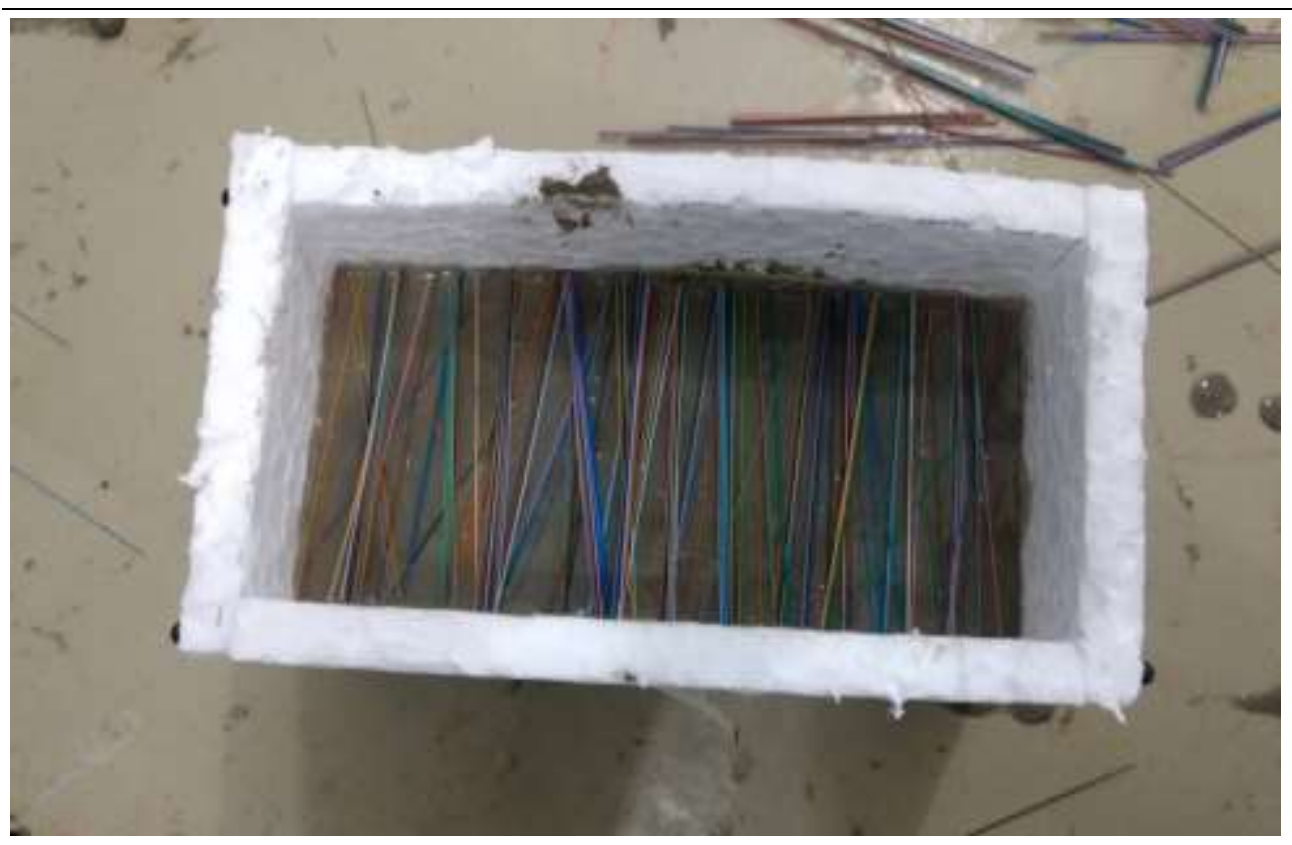

Figura 3: Fibras ópticas de vidro distribuídas no protótipo com a argamassa

Fonte: O próprio autor

\section{RESISTENCIA À COMPRESSÃO}

Para a determinação da resistência à compressão da argamassa no estado endurecido, foi seguido o procedimento descrito na NBR 13279 (ABNT, 2005): Resistência à tração na flexão e à compressão logo em seguida foi elaborado o Gráfico 02.

Gráfico 2: Resistência à compressão

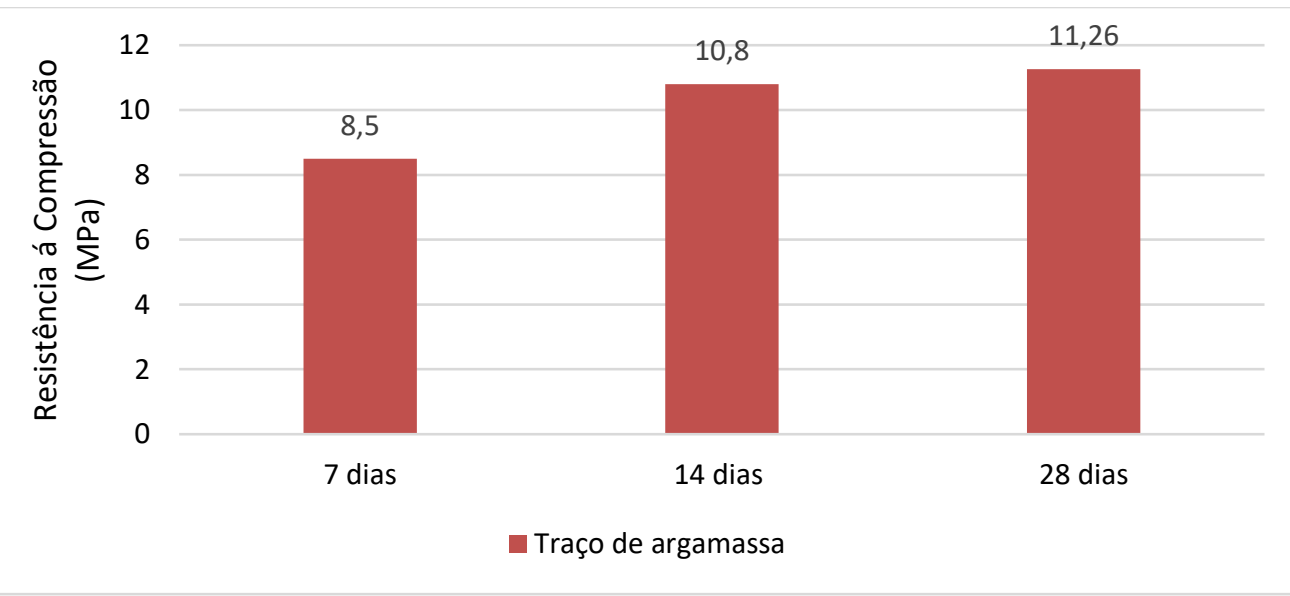

Fonte: O próprio autor 
RESISTENCIA À TRAÇÃO NA FLEXÃO

Para a determinação da resistência à tração na flexão da argamassa no estado endurecido, foi seguido o procedimento descrito na NBR 13279 (ABNT, 2005): Resistência à tração na flexão e à compressão, e logo em seguida foi elaborado o Gráfico 03.

Gráfico 3: Resistência à Tração

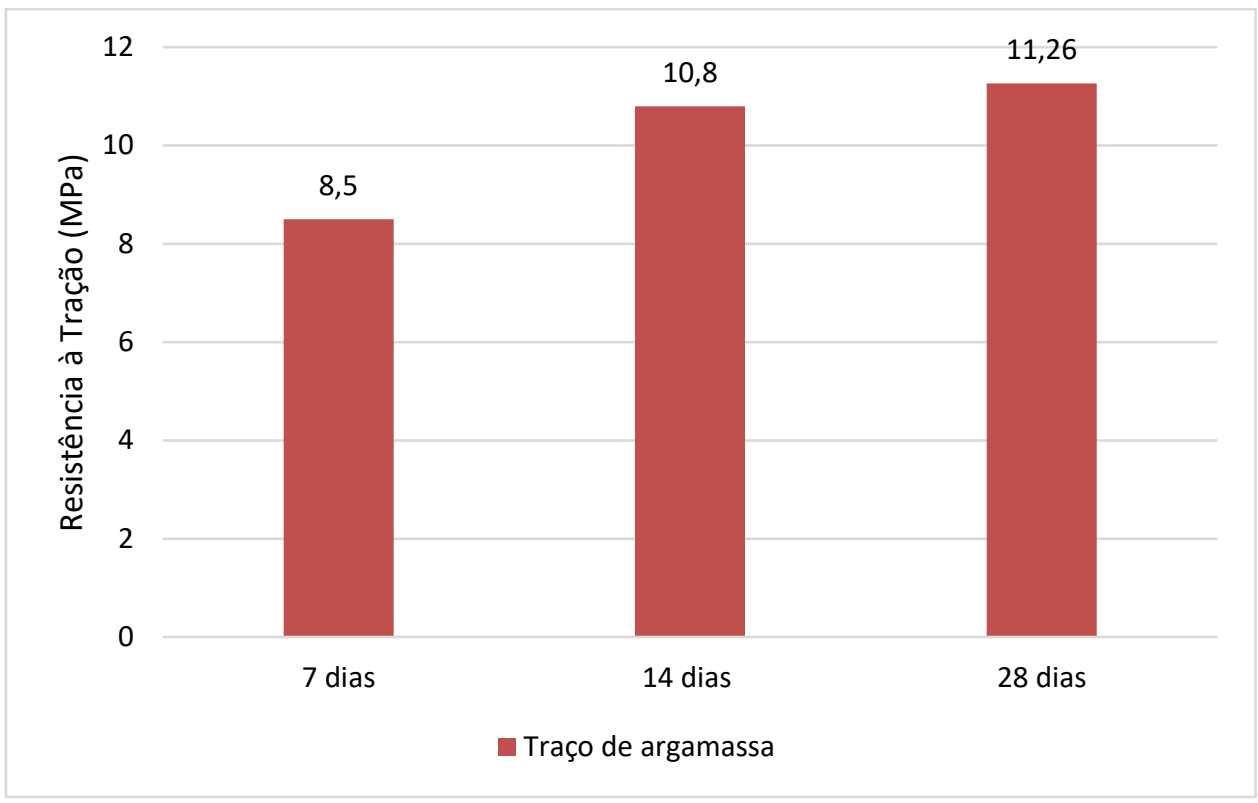

Fonte: O próprio autor

ENSAIO DE LUMINOSIDADE

Para a determinação da luminosidade dos protótipos de argamassa no estado endurecido, foi seguido o procedimento descrito na NBR 5461 (ABNT, 1991), por meio de aparelho luxímetro, e logo em seguida foi elaborado a tabela 08. 
Tabela 08 - Ensaio de luminosidade

\begin{tabular}{lll}
\hline PROTÓTIPOS HORÁRIO & Transmissão de luz \\
\hline
\end{tabular}

Protótipo com fibras ópticas poliméricas $\quad$ 12h00min manhã 387 lux

Protótipo com fibra ópticas de vidro 12h00min manhã 75 lux

\begin{tabular}{lll}
\hline PROTÓTIPOS & HORÁRIO & Transmissão de luz \\
\hline Protótipo com fibras ópticas poliméricas & 16h00min tarde & 339 lux \\
& & \\
\hline
\end{tabular}

\section{CONCLUSÃO}

Nos dias de hoje cada vez mais a sociedade está se tornando mais consciente, buscando meios de preservar tudo a sua volta, e na construção civil não é diferente, diversas pesquisas são desenvolvidas para que venham se descobrir novas incorporações para assim criar novos materiais que sejam benéficos para a mesma.

Dentre estes materiais estudados entra o concreto que é o segundo produto mais utilizado pelo homem. Tendo isso como base, o concreto translúcido foi desenvolvido em 2001 na Hungria e chega com a proposta de iluminar ambientes, para assim, haver uma economia de energia, devido ao aproveitamento da luz do sol.

Atualmente no Brasil, esse produto não é comercializado, porém existem pesquisas em cima das suas vantagens. A principal vantagem do emprego das fibras ópticas na confecção do bloco de argamassa é a penetração de luz através do material. 
A partir da adição das fibras nos compósitos cimentícios foram estudadas as influências da adição das fibras, a fim de, saber qual das duas fibras, a fibra óptica de vidro ou a fibra óptica polimérica, tem maior translucidez quando empregada ao bloco de argamassa.

Partindo disso, esse trabalho teve como objetivo, apresentar um estudo teórico do concreto translúcido e suas propriedades. Após o estudo laboratorial para descobrir qual das duas fibras era a melhor para ser empregada no bloco de argamassa quando o quesito é translucidez e se o bloco com a adição das fibras não alteraria suas propriedades. Esse estudo prático implicou na dosagem, na confecção de corpos de prova e na confecção dos blocos de argamassa adicionando-se a fibra óptica de vidro e a fibra óptica polimérica. Foram realizados ensaios para a determinação da trabalhabilidade, da massa específica e da resistência à compressão da argamassa, além do ensaio de luminosidade.

Logo, após o ensaio de luminosidade a quantidade de lux obtida no protótipo com as fibras ópticas poliméricas foi consideravelmente maior que o lux obtido no protótipo com adição de fibra óptica de vidro, sendo assim, chega-se ao final desta pesquisa, concluindo-se que a fibra óptica polimérica adicionada a argamassa tem maior translucidez do que a fibra óptica de vidro.

\section{REFERÊNCIAS}

ASSOCIAÇÃO BRASILEIRA DE NORMAS TÉCNICAS. NBR 5461: Lighting - Terminology. Rio de Janeiro, 1991.

ASSOCIAÇÃO BRASILEIRA DE NORMAS TÉCNICAS. NBR 11578: Cimento Portland composto. Rio de Janeiro, 1997.

ASSOCIAÇÃO BRASILEIRA DE NORMAS TÉCNICAS. NBR 13276: Argamassa para assentamento e revestimento de paredes e tetos - Preparo da mistura e determinação do índice de consistência. Rio de Janeiro, 2002.

ASSOCIAÇÃO BRASILEIRA DE NORMAS TÉCNICAS. NBR 13277: Argamassa para assentamento e revestimento de paredes e tetos - Determinação da retenção de água. Rio de Janeiro, 1995.

ASSOCIAÇÃO BRASILEIRA DE NORMAS TÉCNICAS. NBR 13278: Argamassa para assentamento e revestimento de paredes e tetos - Determinação da densidade de 
massa e do teor de ar incorporado. Rio de Janeiro, 1995.

ASSOCIAÇÃO BRASILEIRA DE NORMAS TÉCNICAS. NBR 13279: Argamassa para assentamento e revestimento de paredes e tetos - Determinação da resistência à tração na flexão e à compressão. Rio de Janeiro, 2005.

HENRIQUES, T. S. Análise da influência da fibra óptica polimérica inserida em blocos de argamassa. 2013. 180 f. Dissertação (Mestrado) - Pós-graduação em Engenharia Civil. UFRGS, Universidade Federal do Rio Grande do Sul, Porto Alegre.Henriques (2013 apud TANESI, 1999),

RESTREPO, L.M.C. Concreto Translúcido: estudo experimental sobre a fabricação de painéis de concreto com fibra ótica e as suas aplicações na arquitetura. 2013. 178 f. Dissertação (Mestrado) - Pós graduação em Arquitetura e Urbanismo. UnB, Universidade de Brasília, Brasília.

TUTIKIAN, B. F. Concreto translúcido pode ir além da estética. 2009. Disponível em: < http://www.cimentoitambe.com.br/concreto-translucido-pode-ir-alem-daestetica/ >. Acesso em: 10 mar. 2018.

ZTT. Fibra óptica - o processo de fabricação e os tipos de fibra. Disponível em: < http://www.zttcable.com.br/fibra_optica/ >. Acesso em: 20 mai. 2018. 